\title{
Al querido maestro Hernán Montecinos Barrientos
}

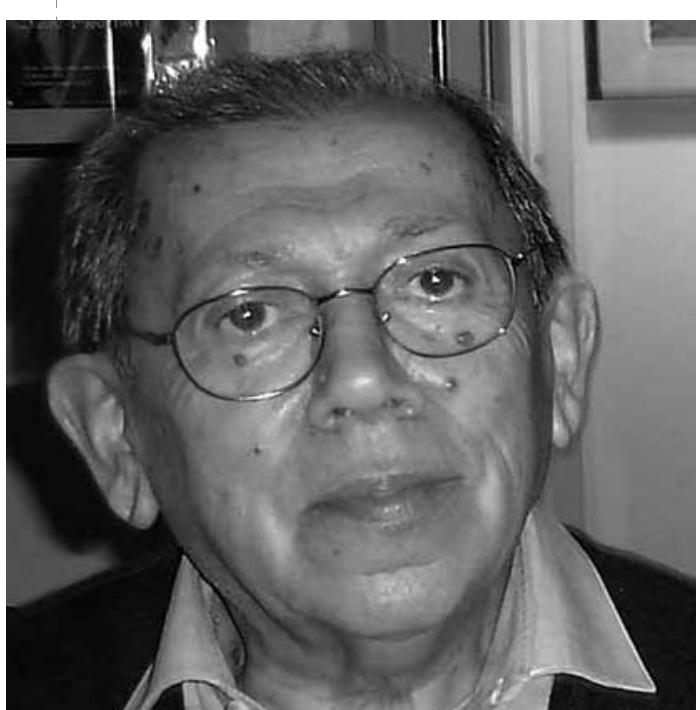

Hernán decidió alejarse en puntillas para no desasosegar a sus amigos, en la madrugada de un lunes de diciembre. Y es que pasó por el mundo casi levitando, en una suerte de ingravidez que le permitía contemplar el andar de los días con la serenidad de un monje. Sus escalas en tierra firme le conectaban con un mundo vertiginoso y con su propia actividad incesante, que repartía entre la Universidad, el Colegio de Arquitectos, el Consejo de Monumentos Nacionales o la Fundación de Amigos de las Iglesias de Chiloé. Entre sus lecturas y meditaciones impartía clases, dictaba conferencias, elaboraba textos. Obtenía nutrientes de la interminable biblioteca que edificó a lo largo de su vida, como también de los persistentes viajes al sur, donde se apertrechaba de voces gentiles, de encuentros afectuosos, de miradas fraternas, de paisajes refrescantes.

Tuvimos la fortuna de convivir largamente con Hernán en el Departamento de Historia. Aparecía siempre con tranco raudo, como si fuera a abordar un tren en marcha. Pero el primer saludo con un colega lo detenía. Entonces hablaba sin apuro, regalando su palabra a todo aquel que quisiera escucharle. Cada vez fue menos sedentario: doce columnas de carpetas azules, desordenadamente dispuestas en la cubierta de su escritorio, le impedían realizar allí cualquier actividad. Ya ni siquiera recordaba el contenido de esas carpetas, pero tampoco se afanó en averiguarlo. Y cuando abandonaba la oficina -más veloz que cuando llegaba-, detrás de sí dejaba la estela de un hombre bueno; también dejaba, a menudo, unas cuantas cuartillas de letra casi indescifrable que atesoraban la certera solución de algún problema o abrían la ventana hacia un campo inexplorado.

Durante muchos años Hernán nos ayudó a desgastar la alfombra del pasillo que conducía a todas las oficinas del Departamento de Historia. Iba y venía; salía y entraba, siempre ágil y resuelto. Los diálogos eran breves y cálidos. Muy de tarde en tarde tenían relación con nuestra actividad cotidiana. Las más de las veces, se trataba de algún comentario festivo. Y es que encontrarse con Hernán hacía bien: significaba darse cuenta de que nada era difícil ni grave; nada merecía la angustia ni el insomnio: a Hernán todo le resultaba sencillo. Desde escribir el prólogo de un libro hasta presentarse en el auditórium para dictar una clase magistral.

Desplegaba su sonrisa desde lejos. A un paso de distancia, solíamos darnos la mano a la altura de nuestras cabezas -nos favorecía la similar estatura- como un tácito homenaje a don Roberto Montandón, que había impuesto esa singular manera de saludar. Y reíamos con ganas, sabiendo que estábamos exagerando hasta la caricatura. Venía, entonces, la recompensa: de su bolsillo hacía aparecer otro caramelo, como el que ya había puesto en su boca.

De habérselo propuesto, Hernán habría escrito muchos libros. Pero quizás no pudo contra su humildad. Las cuartillas manuscritas -tatuadas con su caligrafía sísmica- alcanzan unos cuantos miles. Sospecho, sin embargo, que prefería la palabra oral. Se le hacía fácil, casi un verdadero juego que ponía en práctica ante la menor provocación. Un sinnúmero de sus pensamientos sabios llegaron a recalar en oídos atentos. Si no fue así, iqué importa! Muchos más, seguramente, están en el aire; permanecen agazapados, esperando el momento para visitarnos sin anuncio. Pensamientos que llegarán raudos, se detendrán, harán su trabajo sin apuro y desparecerán veloces, como para abordar un tren en marcha.

Las campanas del sur, mientras tanto, tañerán su nombre por mucho tiempo.

Hasta siempre, querido Hernán. 